\title{
APLIKASI TABUNGAN PONDOK PESANTREN DAYAH PERBATASAN DARUL AMIN KUTACANE ACEH TENGGARA MENGGUNAKAN ALGORITMA KEAMANAN AES BERBASIS WEB
}

\author{
M. Julkarnain ${ }^{1}$, Shinta Esabella ${ }^{2 *}$, Brenny Prasetyo Waty ${ }^{3}$ \\ ${ }^{1,2,3}$ Teknik Informatika, Universitas Teknologi Sumbawa \\ email: shinta.esabella@uts.ac.id
}

\begin{abstract}
Abstrak : Penelitian ini bertujuan untuk merancang dan membangun Aplikasi Tabungan Pondok Dayah Perbatasan Darul Amin Kutacane Aceh Tenggara Menggunakan Keamanan AES Berbasis Web (1) Dapat membantu memudahkan administrasi Dayah untuk mengelola penyimpanan data, menghitung jumlah uang tabungan secara otomatis dan proses laporan keuangan tabungan lebih mudah dengan menggunakan aplikasi yang terkomputerisasi. (2) Aplikasi tabungan ini berbasis web dengan menggunakan algoritma keamanan AES pada menu login nya dan data santrinya. Penelitian ini termasuk ke dalam penelitian kualitatif yang bersifat deskriptif. Pembangunan Aplikasi ini menggunakan bahasa pemograman PHP dan MySQL untuk basis datanya. Dalam penelitian ini penulis menggunakan metode pengumpulan data dengan observasi, wawancara, dan studi pustaka, pemodelan Aplikasi menggunakan model terstruktur yaitu ERD (Entity Relationship Diagram), DFD (Data Flow Diagram), Flowmap dan HIPO (Hierarchy Plus Input-Process Output), sedangkan pengujian aplikasi dengan menggunakan metode black box testing yaitu menguji dari segi fungsional aplikasi.
\end{abstract}

\section{Kata Kunci : Web, Tabungan, AES, Black box Testing}

\begin{abstract}
This study aims to design and build a Darul Amin Border Pondok Dayah Savings Application, Kutacane Aceh Tenggara Using Web-Based AES Security (1) Can help facilitate Dayah administration to manage data storage, calculate the amount of savings money automatically and process savings financial statements more easily by using the computerized application. (2) This savings application is web-based using the AES security algorithm on the login menu and the student data. This research is included in descriptive qualitative research. This application development uses the PHP and MySQL programming languages for the database. In this study, the authors use data collection methods by observation, interviews, and literature study, application modeling uses a structured model, namely ERD (Entity Relationship Diagram), DFD (Data Flow Diagram), Flowmap and HIPO (Hierarchy Plus Input-Process Output), while testing the application using the black box testing method, namely testing in terms of application functionality.
\end{abstract}

Keywords: Web, Savings, AES, Black box Testing

\section{PENDAHULUAN}

Pondok pesantren adalah sebuah tempat atau pendidikan dimana para siswa tinggal dan belajar di bawah bimbingan tenaga pendidik yang dikenal dengan sebutan kiyai dan memiliki asrama sebagai tempat tinggal siswa atau sering disebut dengan santri untuk sementara waktu. Para santri ditempatkan dalam komplek yang didalam pondok tersebut menyediakan tempat ibadah (masjid) untuk beribadah, ruang belajar, dan kegiatan lainnya. Pondok pesantren adalah dua istilah yang menunjukkan satu arti, pesantren adalah tempat belajar para santri sedangkan pondok berarti rumah atau tempat tinggal. Selain itu, kata pondok berasal dari bahasa arab funduq yang artinya asrama atau penginapan. Dipulau jawa sebagian besar menggunakan istilah pondok pesantren, sedangkan di Aceh disebut dengan istilah Dayah. Pesantren juga sering disebut sebagai lembaga pendidikan yang mengajari tentang keagamaan pada umumnya dengan cara nonklasikal, dimana seorang kiai mengajarkan ilmu keagamaan kepada santri yang bergantung pada kitab-kitab yang ditulis dalam bahasa Arab oleh para ulama di abad pertengahan, kepada santri yang tinggal di pondok (asrama) di dalam pesantren tersebut.

Dayah Perbatasan Darul Amin adalah salah satu pondok pesantren yang terletak diperbatasan antara Aceh Tenggara dan Sumatra Utara, Dayah ini terletak di Desa Tanoh Alas, Kecamatan Babul Makmur, Kabupaten Aceh Tenggara, Provinsi Aceh. Dayah Perbatasan Darul Amin didirikan pada tanggal 1998 atas inisiatif pemerintah Aceh Tenggara selain tempat edukasi islam, Dayah ini didirikan juga sebagai konter dari pengaruhpengaruh negatif yang datang dari luar Aceh yang biasanya melalui perbatasan Sumatra UtaraAceh. Pondok pesantren Dayah Perbatasan Darul Amin ini selain mengadakan belajar mengajar, pondok ini juga mengadakan banyak programprogram lainnya salah satu program tersebut adalah tabungan santri. Tabungan santri dinilai bermanfaat dalam mengajarkan santri untuk hemat dan program ini juga meminimalisir kehilangan uang dipondok, santri juga belajar untuk menyisihkan uang yang diberikan orang tua, dan bagi santri yang kurang mampu tabungan ini bisa melakukan cicilan dan membantu untuk meringankan uang bulanan pesantren, program menabung ini tidak bersifat wajib bagi seluruh santri, akan tetapi santri dianjurkan untuk menabung dengan alasan jika terjadi kehilangan 
di pondok, maka pihak pondok tidak bertanggung jawab atas kehilangan tersebut.

Sistem tabungan yang berjalan pada pondok ini masih menggunakancara manual, yaitu dengan pembukuan. Masalah yang sering terjadi dengan sistem manual ini adalah sering kehilangan buku tabungan, sehingga membutuhkan waktu pencarian data siswa ketika ingin memasukan data dan transaksi

penyetoran, dengan jumlah santri di Dayah Perbatasan Darul Amin saat ini mencapai 665 santri, maka akan memakan waktu yang cukup banyak, jika terjadi kesalahan data maka harus melakukan pengecekan ulang terus menerus untuk menghindari kesalahan, harus melakukan perhitungan dengan terus menerus jika dilakukan transaksi penyetoran maupun penarikan tabungan, kesalahan juga sering terjadi dalam pengelolahan data serta penyimpanan dan perawatan dokumen yang masih berbentuk kertas, terkadang beberapa berkas yang hilang dan dapat mengakibatkan keamanan berkas tidak terjaga. Seperti yang disampaikan oleh Kepala Keuangan Pondok Pesantren Dayah Perbatasan Darul Amin, Ustadz Muhammad Anggung, Mp, dalam hasil wawancara yang penulis lakukan, beliau menyampaikan keingianan bahwa adanya aplikasi khusus untuk tabungan Dayah yang mempunyai keamanan data pada berkas yang akan disimpan untuk memudahkan bagian keuangan Dayah Perbatasan Darul Amin dalam proses mendata keuangan tabungan dengan keamanan data yang aman.

Berdasarkan masalah diatas maka Dayah Perbatasan Darul Amin membutuhkan sebuah aplikasi tabungan pondok, maka dibutuhkan perancangan aplikasi tabungan yang dapat mendata santri dan keuangan yang mudah digunakan dan menjaga data agar tetap aman. Dengan adanya aplikasi ini diharapkan dapat memudahkan administrasi pondok untuk mencari data dengan waktu yang sangat efisien, sehingga kesalahan dan kehilangan data dapat diatasi. Aplikasi tabungan ini berbasis web dengan menggunakan algoritma keamanan AES pada menu login nya.

Advanced Encryption Standard (AES) adalah kerangka kerja pengkodean non-feistle karena AES menggunakan bagian-bagian yang secara konsisten memiliki invers dengan panjang blok 128. AES ( Advanced Encryption Standard) merupakan algoritma cipher yang cukup aman untuk melindungi data atau informasi yang bersifat rahasia, kelebihan AES yaitu dilihat dari segi jenis kunci yang simetri maka kecepatan operasi (komputasi) lebih tinggi bila dibandingkan dengan algoritma asimetrik dan adapun kekurangan AES adalah dari segi jenis kunci yang simetris, maka akan terjadi kesulitan dalam manajemen kunci. Hal ini terjadi karena untuk setiap pengiriman dan penerimaan data dengan pengguna yang berbeda dibutuhkan kunci yang berbeda pula. Namun penulis tertarik untuk memanfaatkan keamanan AES untuk aplikasi tabungan, untuk mengamankan data dengan tujuan agar tidak dapat dirusak oleh pihak lain, hanya administrasi pondok yang mengetahui kunci enkripsi dan deskripsi tersebut, keamanan data sangat penting untuk mendapatkan data sehingga tidak dirusak oleh orang lain yang membawa kerugian yang sangat besar.

Diharapkan dengan adanya Aplikasi Tabungan Pondok Pesantren Dayah Perbatasan Darul Amin Kutacane Aceh Tenggara Menggunakan Algoritma Keamanan AES Berbasis Web yaitu dapat mendata santri dan keuangan dengan sangat mudah digunakan dan dapat menjaga data agar tetap aman. Dengan adanya aplikasi ini sangat memudahkan untuk mencari data dengan waktu yang sangat efisien, sehingga kesalahan dan kehilangan data dapat diatasi.

\section{METODOLOGI}

berikut :

Metodologi pada penelitian ini yaitu sebagai

\section{Metode penelitian}

Metode penelitian yang digunakan dalam penelitian ini adalah kualitatif . Kualitatif merupakan salah satu pendekatan yang secara primer menggunakan paradigm pengetahuan berdasarkan pandangan partisipator atau keduanya dengan stategi pendekatan salah satunya adalah studi kasus untuk mengumpulkan data penting secara terbuka terutama dimaksudkan untuk mengembangkan tema-tema dari data [1]

Secara umum terdapat tiga macam teknik pengumpulan data yaitu, wawancara, obeservasi dan dokumentasi.

1. Wawancara

Metode pengumpulan data dengan cara melakukan wawancara tatap muka dengan staf yang berangkutan guna mendapatkan data yang dibutuhkan dan informasi dengan jelas tentang proses pembuatan Aplikasi Tabungan Dayah Perbatasan Darul Amin Menggunakan Keamanan AES berbasis Web.

2. Observasi

Obsevasi pada teknik ini penulis melakukan survei ke Dayah Perbatasan Darul Amin untuk mengindetivikasi objek dan mengumpulkan data-data yang berhubungan dengan Aplikasi yang akan di bangun. 


\section{Dokumentasi}

Dokumentasi merupakan suatu cara untuk mendapatkan data dan informasi dari bagian yang bersangkutan berupa arsip, dokumen, laporan, dan gambar yang akan ditelaah untuk pendukung penelitian.

\section{Metode pengembangan perangkat lunak}

Metode pengembangan perangkat lunak yang digunakan dalam penelitian ini adalah metode spiral model interaksi berbasis risiko generator digunakan untuk mengelola pemrograman dengan berbagai mitra kerangka kerja yang serius. Model spiral adalah model pengukuran pemrograman pengembangan yang menggabungkan ide iteratif dari pembuatan prototyping dengan bagian yang terkontrol dan disengaja dari model waterfall [2][3].

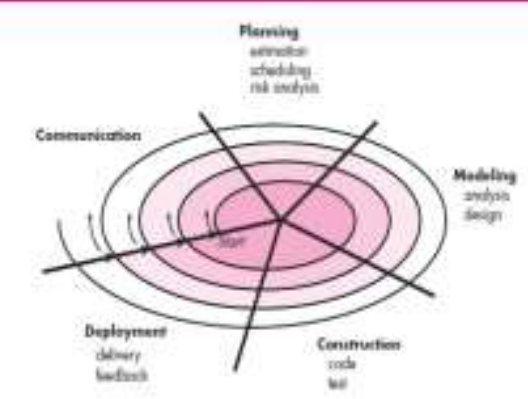

Gambar 1. Metode Spiral (Pressman, 2012)

Model spiral dibagi menjadi beberapa bagiankerangka latihan sistem, atau disebut wilayah tugas, di antara beberapa zona tugas. Fase model dapat secara singkat dijelaskan sebagai berikut :

\section{Communication}

Tahap ini berhubungan dengan komunikasi antara pihak-pihak yang terlibat dalam pengembangan softaware (seperti: system analyst) dengan pelanggan (user). Tujuannya adalah memperbaiki dan mengembangan software sesuai kebutuhan dan keinginan hingga memuaskan pelanggan.

\section{Planning}

Tahap ini berhubungan dengan komunikasi antara pihak-pihak yang terlibat dalam pengembangan softaware (seperti: system analyst) dengan pelanggan (user).

\section{Modeling dan analysis}

Tahapan ini adalah tahap perancangan dan pemodelan arsitektur sistem yang berfokus pada perancangan struktur data, arsitektur software, tampilan interface serta gambaran-gambaran umum dari perancangan yang akan dibangun

\section{Contuction}

Aktivitas yang dibutuhkan untuk pembangunan perangkat lunak, pengujian, instalasi dan penyediaan pengguna atau dukungan pelanggan, seperti pelatihan penggunaan perangkat lunak dan dokumen seperti buku petunjuk perangkat lunak.

\section{Deployment}

Pada tahap evaluasi, system analyst membutuhkan masukan dan tanggapan dari para user dalam mengevaluasi perangkat/produk yang diuji dan memastikan bahwa produk dibutuhkan sesuai ketentuan yang telah dibicarakan diawal dengan user. System analyst memastikan pelanggan puas dengan produk yang akan dihasilkan untuk menjawab persoalan bisnis mereka. Selain itu, system analyst harus tetap memantau resiko yang akan terjadi seperti faktorfaktor yang dapat menyebabkan cost overrun (pembengkakan biaya).

\section{Flowmap yang Berjalan}

Berdasarkan hasil wawancara yang dilakukan peneliti di pondok pesantren Dayah Perbatasan Darul Amin Kutacane Aceh Tenggara diketahui sistem yang berjalan saat ini masih manual terlihat pada gambar dibawah ini :

\section{Flowmap pendaftaran.}

Berikut ini merupakan gambar data flowmap pendaftaran sistem yang berjalan saat ini pada Dayah Perbatasan Darul Amin.

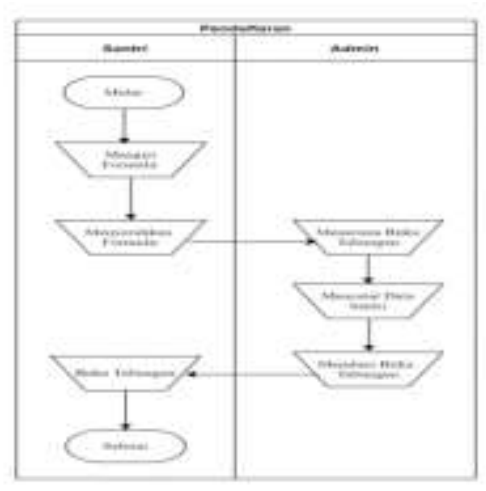

Gambar 2. Flowmap yang Berjalan 
a. Flowmap Sistem transaksi yang Berjalan

Berikut ini flowmap tabungan dan penarikan yang berjalan saat ini:

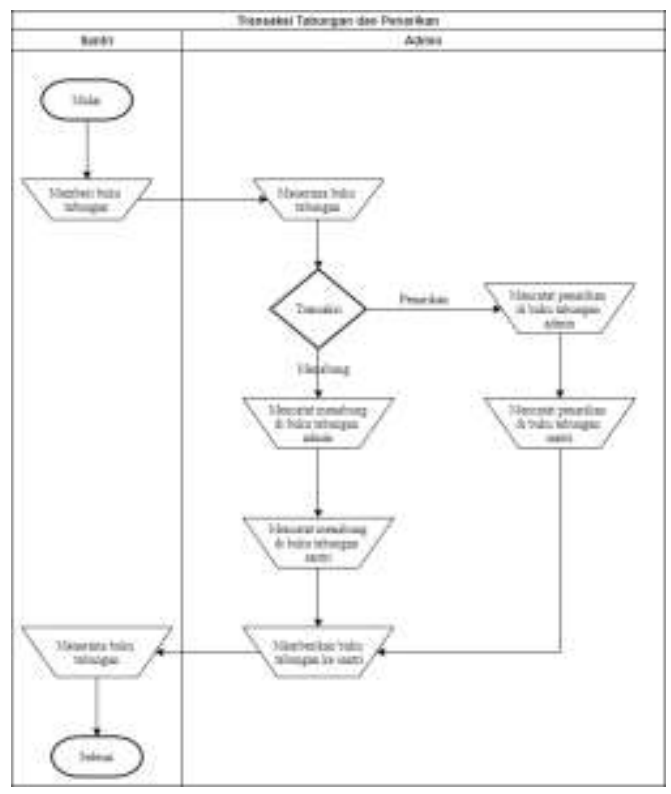

Gambar 3. flowmap transaksi yang berjalan.

\section{Flowmap yang Diusulkan}

a. Flowmap Aplikasi Usulan Pendaftaran

Berikut ini merupakan gambar data flowmap pendaftaran yang yang akan diususlkan pada Dayah Perbatasan Darul Amin.

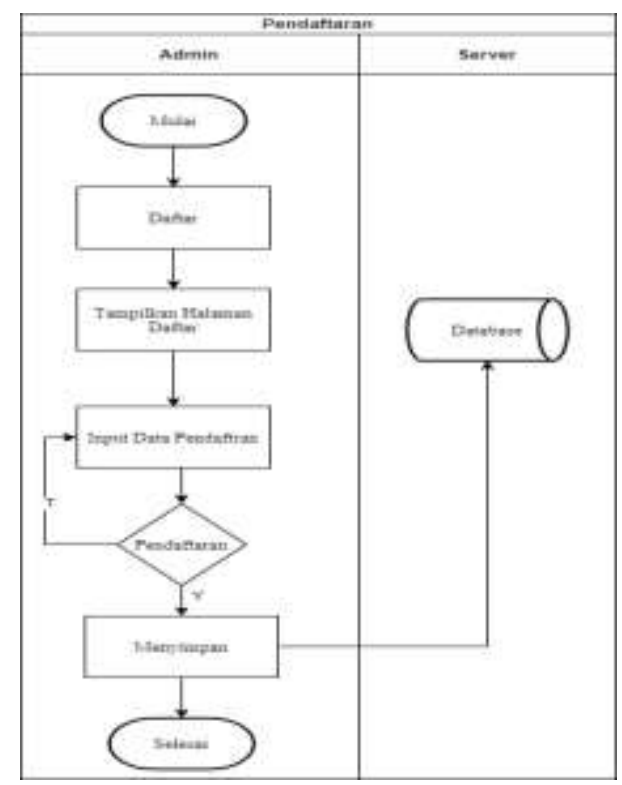

Gambar 4. flowmap pendaftaran diususlan

\section{a. Flowmap transaksi yang diusulkan}

Berikut ini merupakan gambar data flowmap menabung dan penarikan yang berjalan saat ini pada Dayah Perbatasan Darul Amin.

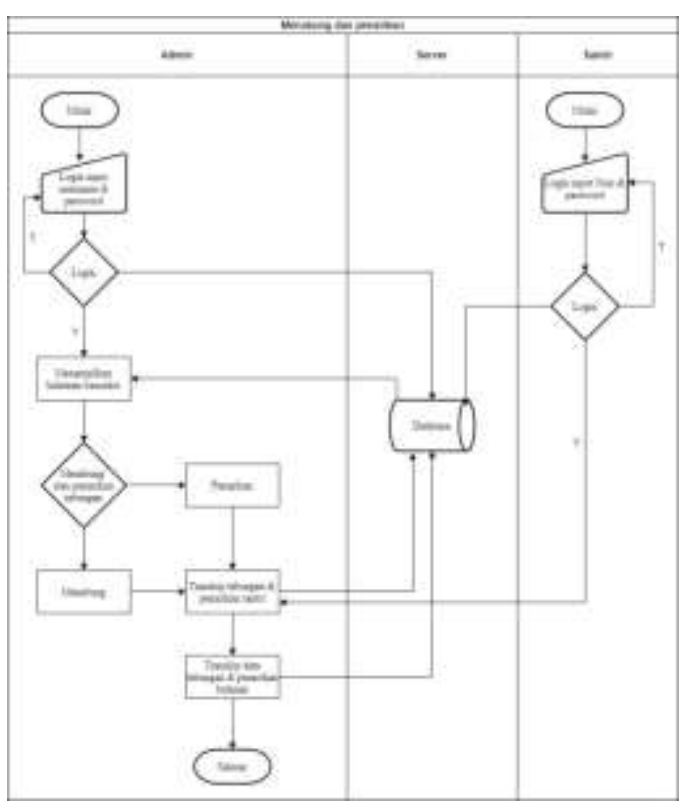

Gambar 5. Flowmap transaksi usulan

\section{HASIL DAN PEMBAHASAN}

Hasil dan pembahasan pada penelitian ini dapat diuraikan sebagai berikut :

\section{Diagram Context}

Diagram context menggambarkan proses secara garis besar apa yang terjadi pada program aplikasi ini. Berikut merupakan gambar diagram konteks Aplikasi Tabungan :

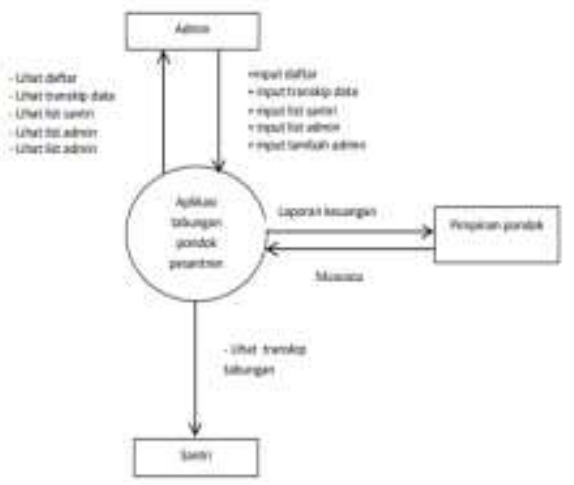

Gambar 6. Diagram Context

Santri hanya dapat melihat transkip data tabungan melalui admin, karna di pondok pesantren santri dilarang menggunakan barang elektronik. Dan laporan keuangan ke pimpinan pondok pesantren dilakukan melalui laporan langsung menggunakan hardcopy atau kertas. 


\section{Data Flow Diagram}

Berikut merupakan gambar data flow diagram Aplikasi Tabungan Pondok Pesantren Dayah Perbatasan Darul Amin:

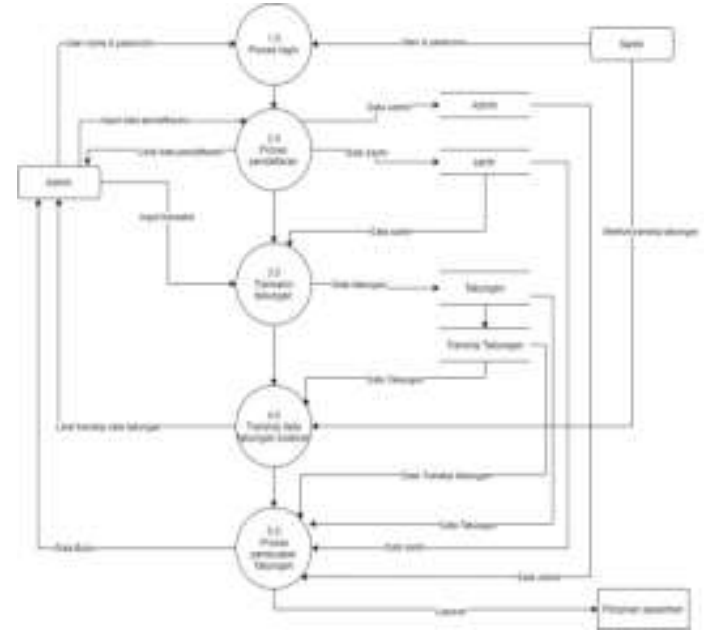

Gambar 7 Data Flow Diagram

Aplikasi Tabungan Pondok Pesantren Dayah Perbatasan darul amin telah menggambarkan tentang semua alur kerja aplikasi yang dibangun. Dimana terdapat proses daftar, transaksi tabungan dan transkip data keuangan tabungan, melaporkan setiap bulan nya ke pimpinan Pondok Pesantren Dayah Perbatasan Darul Amin, aplikasi tabungan pondok pesantren ini hanya diakses oleh admin keuangan pondok pesantren.

\section{Entity Relationship Diagram}

Adapun ERD (Entity Relationship Diagram) dari Aplikasi Tabungan Pondok Pesantren Dayah Perbatasan Darul Amin Kutacane Aceh Tenggara ini dapat dilihat pada gambar dibawah ini :

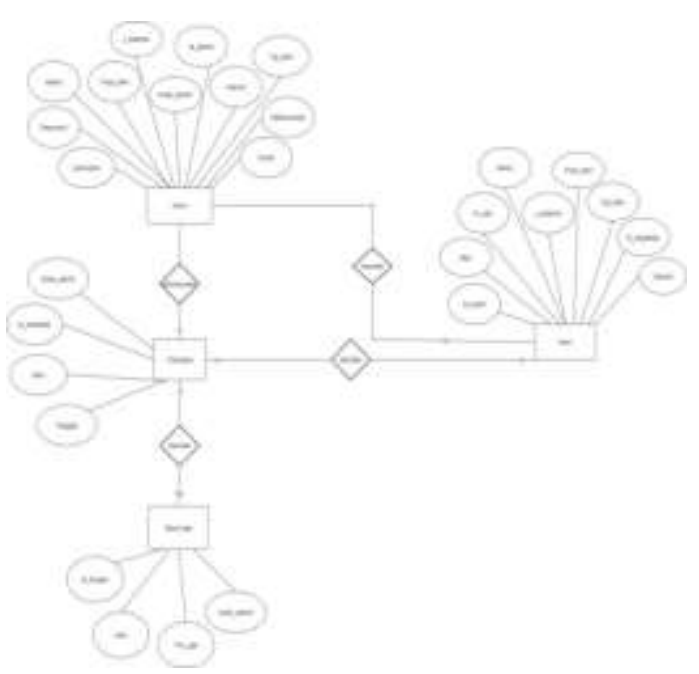

Gambar 8. Entity Relationship Diagram

\section{Relasi antar tabel}

Berikut adalah gambar rancangan relasi antar tabel dalam membangun database Aplikasi Tabungan Pondok Pesantren Dayah Perbatasan Darul Amin Menggunakan Algoritma Keamanan AES sebagai berikut :

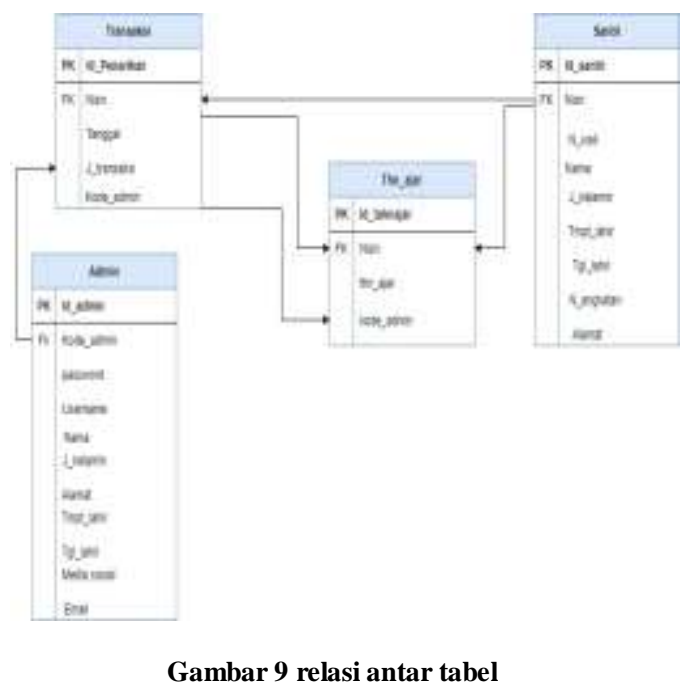

\section{Implementasi Program}

Adapun implementasi program pada aplikasi Tabungan Pondok Pesantren Dayah Perbatasan Darul Amin adalah sebagai berikut :

\section{Tampilan Login}

Adapun tampilan halaman login adalah halaman utama pada aplikasi ini yang memiliki fungsi sebagai berikut :

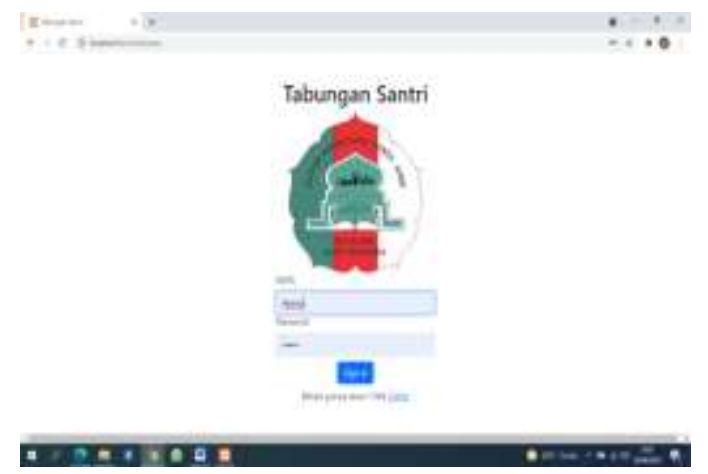

Gambar 9. halaman daftar santri

\section{Tampilan Halaman Data Santri}

\section{a. Tampilan Halaman Menu Santri}

Adapun tampilan halaman bagian daftar santri pada aplikasi ini yang memiliki fungsi sebagai berikut : 


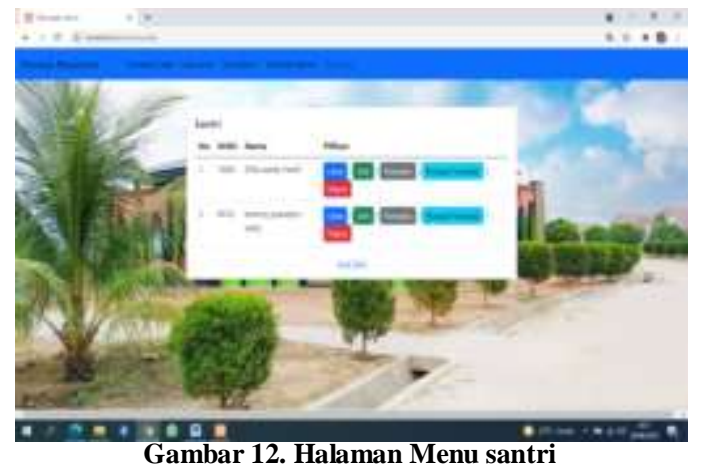

\section{b. Halaman Menu Transaksi}

Adapun tampilan halaman bagian menu transaksi pada aplikasi ini memiliki fungsi sebagai berikut :

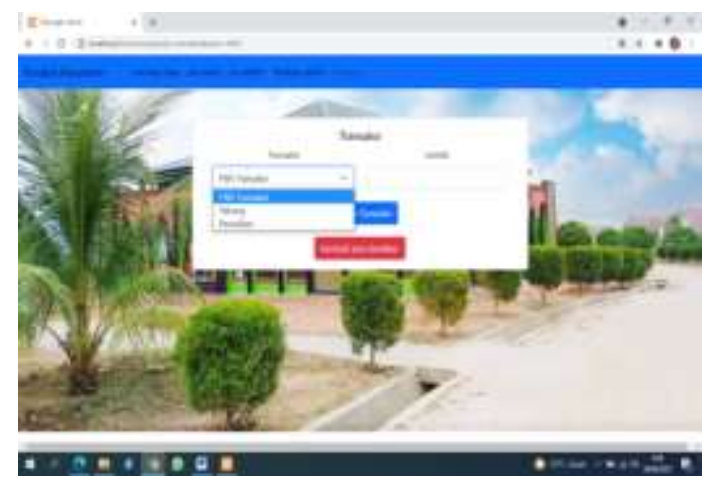

Gambar 13. Halaman menu transaksi

\section{c. Menu Riwayat Transaksi}

Adapun tampilan halaman bagian menu lihat riwayat santri pada aplikasi ini yang memiliki fungsi sebagai berikut:

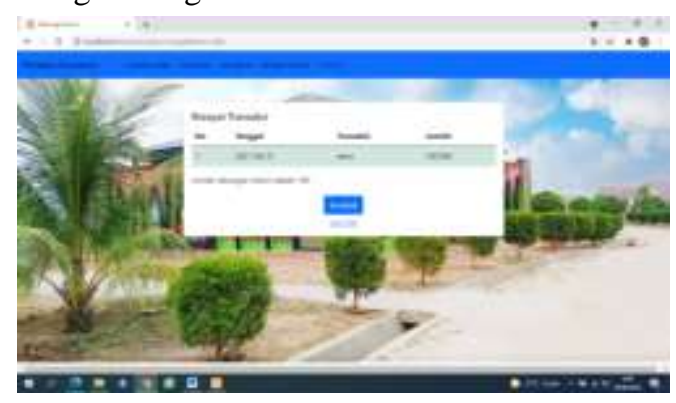

Gambar 13. Rampilan menu riwayat transaksi

\section{d. Lihat Data Santri}

Adapun tampilan halaman bagian lihat data santri pada aplikasi ini yang memiliki fungsi sebagai berikut :

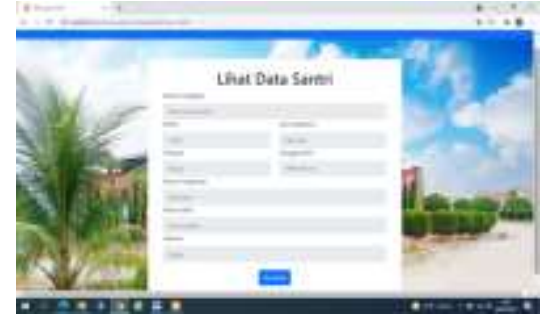

Gambar 14. Lihat Data Santri

\section{Tampilan Halaman Admin}

Adapun tampilan halaman bagian lihat data santri pada aplikasi ini yang memiliki fungsi sebagai berikut :

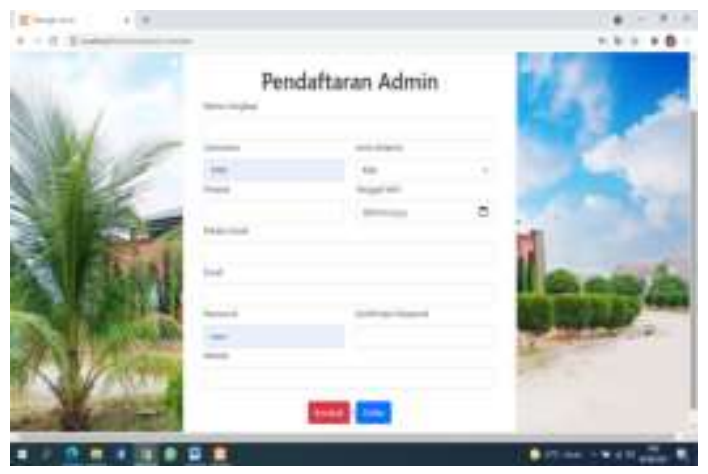

Gambar 15. Tampilan Halaman Admin

\section{Tampilan Halaman List Admin}

Adapun tampilan halaman bagian lihat data santri pada aplikasi ini yang memiliki fungsi sebagai berikut :

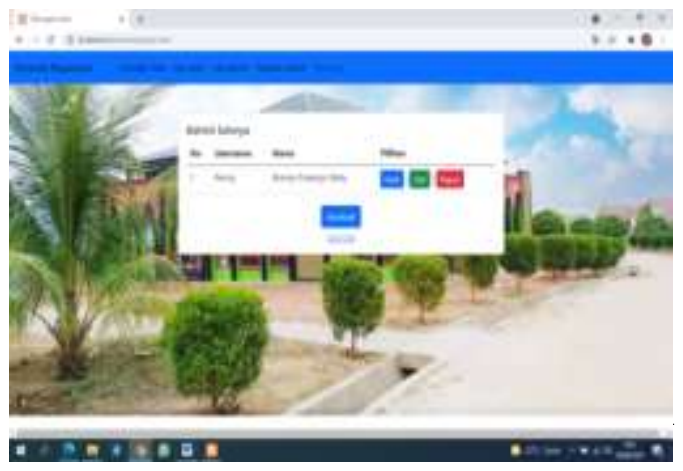

Gambar 16. Tampilan Halaman List Admin

\section{Tampilan Halaman Transkip Laporan Tabungan}

Adapun tampilan halaman bagian transkip laporan tabungan pada aplikasi ini yang memiliki fungsi sebagai berikut:

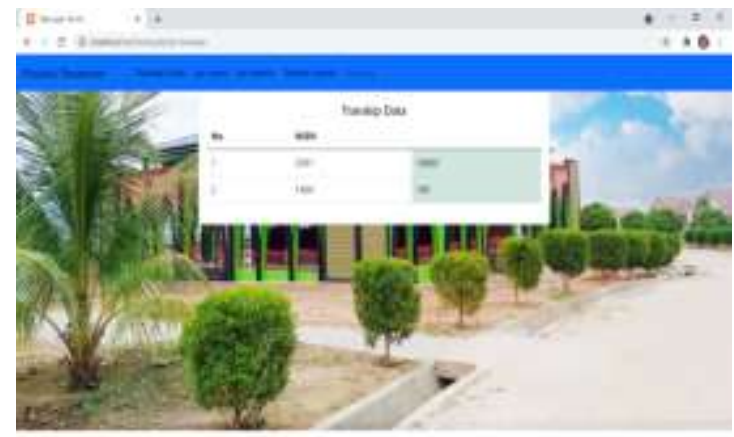

Gambar 17. Tampilan Halaman Laporan 


\section{Keamanan Algoritma AES}

Sistem keamanan AES di aplikasi Pondok Tabungan diimplementasikan pada saat pendaftaran siswa, admin dan login, prosedur keamanan yang diterapkan adalah web mengirimkan kode verifikasi ini yang kemudian diinput ke program Sistem Keamanan AES yang dikembangkan menggunakan enkripsi AES. web Kode keamanan ini harus sesuai dengan profil admin atau admin agar berhasil login. Hasil dari enkripsi program login dengan penerapan sistem keamanan berbasis enkripsi AES (advanced encryption standard) adalah sebagai berikut :

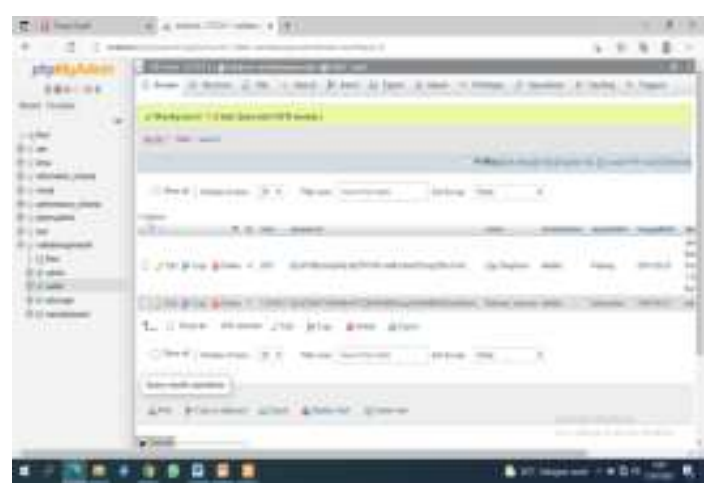

Gambar 18. Tampilan AES

\section{Pembahasan}

Dengan hasil tersebut, dapat dikatakan bahwa tujuan dari penelitian ini sudah tercapai, yaitu membantu pengelolaan tabungan pondok pesantren dayah perbatasan darul amin bahwa penelitian ini memiliki kesamaan dengan dasar teori yang penulis gunakan yakni menggunakan database MySQL sebagai penyimpanan data.

Pada penelitian pertama yang berjudul "Perancangan Program Aplikasi Tabungan Siswa Sekolah Dasar Negeri Cipancar Iv dengan menggunakan Pendekatan Metodologi Rapid Application Development" [4].

Pada penelitian kedua yang berjudul "Sistem Informasi Tabungan Siswa Berbasis Web Pada Sekolah Menengah Kejuruan (Smk) Nusa Putra Kota Tangerang" [5]. Penelitian ini menggunakan metode mengumpulan data kualitatif metode ini memiliki kesamaan dalam pengumpulan data penulis.

Penelitian ketiga yang berjudul "Rancang Bangun Sistem Informasi Pembayaran Dan Tabungan Siswa Pada Bank Mini Artha Mandiri Sekolah Menengah Kejuruan (SMK) Negeri Pringkuku Pacitan"[6]. Bahwa penelitian ini memiliki kesamaan dengan dasar teori yang digunakan oleh penulis yaitu menggunakan bahasa penograman PHP dan MySQL sebagai penyimpanandatanya.
Penelitian keempat yang berjudul "Studi Terhadap Advanced Encryption Standard (AES) Dan Algoritma Knapsack Dalam Pengamanan Data" [7]. Bahwa penelitian ini memiliki keamanan data menggunakan algoritma keamanan untuk mengamankan data.

Penelitian kelima yaitu berjudul "Pengembangan Sistem Keamanan Untuk Toko Online Berbasis Kriptografi AES Menggunakan Bahasa Pemrograman Php Dan MySQL" [8]. Pada penelitian ini memiliki kesamaan dalam mengimplementasi AES ke bahasa pemograman AES dan MySQL sebagai basis datanya.

\section{KESIMPULAN}

Berdasarkan hasil penelitian pada pondok pesantren Dayah Perbatasan Darul Amin Kutacane Aceh Tenggara yang telah selesai penulis bangun yaitu Aplikasi Tabungan Pondok Pesantren Dayah Perbatasan Darul Amin Menggunakan Algoritma Keamanan AES Berbasis Web dengan menggunakan perancangan DFD dan bahasa pemograman PHP dengan Database MySQL, dimana telah menghasilkan aplikasi yang telah diuji menggunakan black box tasting dan berhasil, Aplikasi Tabungan Pondok berhasil dibuat dengan menggunakan bahasa pemograman php, data terekam secara otomatis karena menggunakan proses input secara terkomputerisasi dan data tersimpan di database sehingga lebih mudah dalam proses pendataan santri yang menabung.

\section{DAFTAR PUSTAKA}

[1] Emzir. (2011). Metodologi Penelitian Pendidikan Kuantitatif dan Kualitatif. Jakarta: PT Rajagrafindo Persada.

[2] Pressman, Roger S. (2012). Rekayasa Perangkat Lunak Pendekatan Praktisi Edisi 7. Yogyakarta: Andi Yogyakarta.

[3] Esabella S and Rodianto. (2019). Portal Application Development of Sumbawa Unique Souvenir. International Journal Of Electronics Communication and Computer Engineering. Vol. 10 Issue 5. Page 224-231.

[4] Purnama, H., dkk. (2014). Perancangan Program Aplikasi Tabungan Siswa Sekolah Dasar Negeri Cipancar IV Dengan Menggunkan Pendekatan Metodologi Rapid Application Development. Jurnal Algoritma Sekolah Tinggi Teknologi Garut. ISNN: 23027339 vol.11. 2014.

[5] Suwarto, dkk. (2018). Sistem Informasi Tabungan Siswa Berbasis Web Pada Sekolah Menengah Kejuruan (Smk) Nusa Putra Kota Tangerang. Jurnal (SMK) NUSA PUTRAKOTA TANGERANG. Vol.4 No.2, ISSN: 2461-1409. 
JINTEKS (Jurnal Informatika Teknologi dan Sains)

Vol. 3 No. 3, Agustus 2021, hlm. $401-408$

ISSN 2686-3359 (Online)

DOI Prefix 10.51401

[6] Hapsari, S., dkk. Rancang Bangun System Informasi Pembayaran Dan Tabungan Siswa Pada Bank Mini Artha Mandiri Sekolah Menengah Kejuruan (SMK) Negeri Pringkuku Pacitan. Journal Speed.

[7] Asriyanik. (2017).Studi Terhadap Advanced Encryption Standard(Aes) Dan Algoritma Knapsack Dalam Pengamanan Data. Jurnal Santika : Jurnal Ilmiah Sains dan TeknologiISSN 2088-5407 Volume 7 No 1 Juni 2017.

[8] Candra Benni. (2014). "pengembangan sistem keamanan untuk toko onlen berbasis kriptografi AES menggunakan bahasa pemograman PHP dam MySQL". Jurnal media infotama, Vol, 11, No.1, $\quad$ Februari 2014 